\title{
Post-COVID-19 Symptom Burden: What is Long-COVID and How Should We Manage It?
}

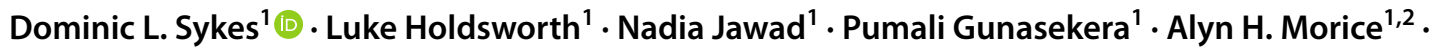 \\ Michael G. Crooks ${ }^{1,2}$
}

Received: 25 November 2020 / Accepted: 27 January 2021 / Published online: 11 February 2021

(c) The Author(s), under exclusive licence to Springer Science+Business Media, LLC part of Springer Nature 2021

\begin{abstract}
The enduring impact of COVID-19 on patients has been examined in recent studies, leading to the description of LongCOVID. We report the lasting symptom burden of COVID-19 patients from the first wave of the pandemic. All patients with COVID-19 pneumonia discharged from a large teaching hospital trust were offered follow-up. We assessed symptom burden at follow-up using a standardised data collection technique during virtual outpatient clinic appointments. Eighty-six percent of patients reported at least one residual symptom at follow-up. No patients had persistent radiographic abnormalities. The presence of symptoms at follow-up was not associated with the severity of the acute COVID-19 illness. Females were significantly more likely to report residual symptoms including anxiety $(p=0.001)$, fatigue $(p=0.004)$, and myalgia $(p=0.022)$. The presence of long-lasting symptoms is common in COVID-19 patients. We suggest that the phenomenon of Long-COVID may not be directly attributable to the effect of SARS-CoV-2, and believe the biopsychosocial effects of COVID-19 may play a greater role in its aetiology.
\end{abstract}

Keywords Long-COVID · COVID-19 · Symptom burden

\section{Introduction}

The lasting symptom burden and impact of COVID-19 on patients has been examined in recent studies [1-4]. These findings have led to the description of post-COVID syndrome (also known as Long-COVID), a syndrome encompassing a protracted course of various physical and neuropsychiatric symptoms that persist for more than 12 weeks without an alternative explanation [5,6]. It is not currently known who is at greatest risk of developing Long-COVID but it is recognised that there is little relationship between the severity of the acute illness and the likelihood of developing Long-COVID [7, 8].

Dominic L. Sykes and Luke Holdsworth have contributed equally to this article.

Dominic L. Sykes

Dominic.sykes@hey.nhs.uk

1 Hull University Teaching Hospitals Trust, Respiratory Clinical Trials Unit, Daisy Building, Castle Hill Hospital, Hull HU16 5JQ, UK

2 Hull York Medical School, Hull, UK
We report the lasting symptom burden of a patient cohort hospitalised with COVID-19 pneumonia during the first wave of the pandemic from a single NHS hospital trust in England. Our findings could have important implications for how healthcare systems should organise services to support these patients.

\section{Methods}

All patients discharged from Hull University Teaching Hospitals NHS Trust after treatment for COVID-19 pneumonia were offered follow-up in accordance with a locally developed clinical pathway. The pathway was based on a published model [3] and amended to reflect local service configuration. Patients were not followed up if their admission was unrelated to COVID-19 or they had only mild symptoms and a normal chest $\mathrm{X}$-ray (CXR). All patients included in our cohort had RT-PCR confirmed COVID-19 pneumonia. Our data do not include those followed up under the local frailty team (care home residents and those with a Clinical Frailty Score $\geq 6[9])$. 
All patients received a follow-up CXR and standardised clinical assessment by a specialist nurse and/or physiotherapist. Those with persistent symptoms or abnormal convalescent chest $\mathrm{X}$-ray were seen in a senior physician-led clinic and further investigations were performed based on clinical need. The clinical pathway is available in the online supplement.

A standard dataset was collected for each patient including demographics, details of acute COVID-19 admission, treatment, and symptom burden at follow-up. Validated questionnaires were used to quantify dyspnoea (MRC dyspnoea scale) and quality of life (5-level EuroQol-5 Dimension also known as EQ-5D-5L); all other symptoms were assessed using a standardised follow-up assessment proforma, directly asking patients whether or not they were currently experiencing specific symptoms. Admission and follow-up CXRs were reviewed and categorised using the British Society of Thoracic Imaging (BSTI) coding for analysis [10]. Electronic patient records were reviewed for analysis of biochemical markers for correlation with followup imaging and questionnaire results.

Statistical analysis comparing symptoms at follow-up were performed using Chi-Square and Mann-Whitney U testing. Analysis comparing biochemical markers was performed using Wilcoxon signed-rank testing. A co-occurrence matrix [11] was created to identify symptom 'clusters' using logistic regression. From this, we analysed pairs of symptoms that had high correlation coefficients and identified groups of symptoms that were commonly reported concomitantly. All analysis was performed with the use of SPSS statistics 26. Reported values are subject to rounding errors.

All data included were recorded as part of routine followup and its inclusion in this study was ratified by the Hull University Teaching Hospitals NHS Trust clinical governance committee.

\section{Results}

A total of 387 patients were identified as having been discharged with a coded diagnosis of COVID-19. Of these, 298 met the criteria for follow-up (admission related to COVID19 pneumonia). 108 were followed up by the local frailty team and their data were not included in this analysis. A further 56 patients were lost to follow-up.

A total of 134 patients (median age $=58$ [range 25-89], $65.7 \%$ male $[n=88])$ attended their follow-up appointments. Patients were followed up at a median of 113 days (range $=46-167)$ post-discharge. Demographics, preCOVID-19 comorbidities, and admission details are displayed in Table 1. All patients had radiological evidence of COVID-19 pneumonia and $87 \%(n=116)$ required oxygen and/or respiratory support. $80 \%(n=107)$ were treated on hospital wards, and $20 \%$ were treated in the intensive care unit (ICU) during their admission.

\section{Symptom Burden at Follow-up}

Breathlessness was the most commonly reported symptom with $60 \%$ of people experiencing increased breathlessness compared to their pre-COVID-19 state. Other common symptoms included myalgia (reported by $51.5 \%$ of patients), anxiety (47.8\%), extreme fatigue $(39.6 \%)$, low mood $(37.3 \%)$, and sleep disturbance $(35.1 \%)$. Females were significantly more likely than males to report anxiety $(p=0.001)$, low mood $(p=0.031)$, myalgia $(p=0.022)$, fatigue ( $p=0.004)$, sleep disturbance $(p=0.009)$, and memory impairment $(p=0.001)$. Higher BMI was associated with myalgia $(p=0.012)$ and fatigue $(p=0.046)$.

There were no significant differences in lasting symptom burden based on the level of care, maximum oxygen, or respiratory support received.

The proportion of patients reporting persistent symptoms diminished with a longer time to follow-up but this trend was not significant. Symptom data are displayed in Table 2 and Fig. 1.

\section{Inflammatory Markers}

The median discharge C-reactive protein (CRP) level was significantly lower than that of admission $(107 \mathrm{mg} / \mathrm{L}$ vs $23 \mathrm{mg} / \mathrm{L}, p<0.001$, Wilcoxon signed-rank test). Of the 76 patients who were tested at follow-up, CRP and white cell count were within the normal range in $84 \%(n=64)$ and $92 \%$ $(n=70)$, respectively.

\section{Radiographic Findings}

130 patients had radiographic evidence of COVID-19 pneumonia at presentation and the remaining 4 patients developed this during the course of their admission. 125 patients had a follow-up CXR, of which 77\% $(n=103)$ were normal (PCVCX 0$)$ and $8 \%(n=10)$ showed a resolution of $\geq 50 \%$ of their abnormalities (PCVCX1). The remainder had persistent non-COVID-related changes. No patients' CXRs were unchanged or had worsening changes. There was no difference in symptom burden at follow-up between those who had follow-up CXRs coded as PCVCX0 and PCVCX1.

\section{Symptom “Clusters"}

Through the use of a co-occurrence matrix [11], we were able to identify 3 symptom "clusters": Cluster A included myalgia and fatigue; Cluster B included low mood, anxiety, and sleep disturbance; and Cluster $\mathrm{C}$ comprised memory impairment, attention deficit, and cognitive impairment. 
Table 1 Baseline demographics, admission data, and clinical follow-up information in all patients

\begin{tabular}{|c|c|c|c|c|}
\hline & All patients $(n=134)$ & Ward-based $(n=107)$ & $\mathrm{ICU}(n=27)$ & $P$-value \\
\hline Age (SD) & $59.6(14.0)$ & $60.9(14.0)$ & $54.7(13.2)$ & $0.038 *$ \\
\hline Male (\%) & $88(65.7)$ & $69(64.5)$ & $19(70.4)$ & 0.565 \\
\hline Length of Stay (range) & $7(1-45)$ & $5(1-45)$ & $13(5-42)$ & $<0.001^{\mathrm{a}}$ \\
\hline BMI (range) & $28.8(17.3-49.8)$ & $28.5(17.3-48.6)$ & $30.7(23.4-49.8)$ & $0.012^{\mathrm{a}}$ \\
\hline \multicolumn{5}{|l|}{ Ethnicity (\%) } \\
\hline White - all & $122(91.0)$ & $100(93.5)$ & $22(81.5)$ & - \\
\hline Black - all & $2(1.5)$ & $2(1.8)$ & $0(0)$ & - \\
\hline Asian - all & $8(6.0)$ & $4(3.8)$ & $4(14.8)$ & - \\
\hline Mixed/other & $2(1.5)$ & $1(0.9)$ & $1(3.7)$ & - \\
\hline \multicolumn{5}{|l|}{ Comorbidities (\%) } \\
\hline Type 1 diabetes & $1(0.7)$ & $1(0.9)$ & $0(0)$ & 0.121 \\
\hline Type 2 diabetes & $30(22.0)$ & $22(20.6)$ & $8(29.6)$ & 0.074 \\
\hline Ischaemic heart disease & $22(16.4)$ & $19(17.8)$ & $3(0.11)$ & 0.102 \\
\hline COPD & $11(8.2)$ & $9(8.4)$ & $2(7.4)$ & 0.135 \\
\hline Asthma & $19(14.2)$ & 17 (15.9) & $2(7.4)$ & 0.078 \\
\hline Hypertension & $55(41.0)$ & $41(38.3)$ & $14(51.9)$ & 0.049 \\
\hline CKD & $6(4.5)$ & $4(3.7)$ & $2(7.4)$ & 0.094 \\
\hline History of VTE & $3(2.2)$ & $3(2.8)$ & $0(0)$ & 0.522 \\
\hline Cancer & $7(5.2)$ & $6(5.6)$ & $2(7.4)$ & 0.113 \\
\hline Home ventilation & $3(2.2)$ & $5(4.7)$ & $2(7.4)$ & 0.113 \\
\hline CVD & $6(4.5)$ & $4(3.7)$ & $2(7.4)$ & 0.544 \\
\hline Smoking history & $59(44.0)$ & $51(47.7)$ & $8(29.6)$ & - \\
\hline Alcohol use & $57(42.5)$ & $46(43.0)$ & $11(40.7)$ & - \\
\hline$\geq 3$ comorbidities & $19(14.2)$ & $15(14.0)$ & $4(14.8)$ & 0.916 \\
\hline \multicolumn{5}{|c|}{ Maximum oxygen/ respiratory support requirement (\%) } \\
\hline Air & $18(13.4)$ & $18(16.8)$ & $0(0)$ & - \\
\hline Nasal cannula/face mask & $80(59.4)$ & $80(74.8)$ & $0(0)$ & - \\
\hline CPAP/ BIPAP & $8(5.9)$ & $6(5.6)$ & $2(7.4)$ & - \\
\hline High flow nasal cannula & $18(13.4)$ & $3(2.8)$ & $15(55.5)$ & - \\
\hline Intubation & $9(6.7)$ & $0(0)$ & $9(33.3)$ & - \\
\hline ECMO & $1(0.7)$ & $0(0)$ & $1(3.7)$ & - \\
\hline \multicolumn{5}{|l|}{ Median admission inflammatory markers } \\
\hline White cell count $\left(\times 10^{9} / \mathrm{L}\right)$ & $6.55(2.4-90.1)$ & $6.25(2.4-90.1)$ & $7.0(3.4-22.2)$ & 0.040 \\
\hline C-reactive protein $(\mathrm{mg} / \mathrm{L})$ & $107(0.4-380)$ & $80(0.4-269)$ & $136(5-380)$ & 0.001 \\
\hline \multicolumn{5}{|l|}{ Median discharge inflammatory markers } \\
\hline White cell count $\left(\times 10^{9} / \mathrm{L}\right)$ & $7.5(2.3-43.9)$ & $6.75(2.3-43.9)$ & $9.35(3.4-14.4)$ & $<0.001$ \\
\hline C-reactive protein (mg/L) & $23(0.4-221)$ & $22.5(0.4-206)$ & $25.5(6.1-221)$ & 0.817 \\
\hline \multicolumn{5}{|l|}{ Median follow-up inflammatory markers } \\
\hline White cell count $(\times 109 / \mathrm{L})$ & $6.6(2.3-21.0)$ & $6.6(2.3-21.0)$ & $8.6(3.6-13.7)$ & 0.094 \\
\hline C-reactive protein $(\mathrm{mg} / \mathrm{L})$ & $2.9(0.2-33)$ & $3.2(0.1-33)$ & $1.8(0.2-11)$ & 0.289 \\
\hline \multicolumn{5}{|l|}{ BSTI COVID-19 admission CXR code } \\
\hline CVCX0 (Normal) & $4(3.0)$ & $4(3.7)$ & $0(0)$ & - \\
\hline CVCX1 (Classical COVID-19) & $92(68.7)$ & $70(65.4)$ & $22(81.5)$ & - \\
\hline CVCX2 (Indeterminate COVID-19) & $23(17.2)$ & $19(17.8)$ & $4(14.8)$ & - \\
\hline CVCX3 (Non-COVID-19; Abnormal) & $8(6.0)$ & $8(7.5)$ & $0(0)$ & - \\
\hline \multicolumn{5}{|l|}{ BSTI COVID-19 Follow-up CXR Code } \\
\hline PCVCX0 (normal, resolved changes) & $103(76.9)$ & $88(82.3)$ & $15(55.6)$ & - \\
\hline PCVCX1 ( $\geq 50 \%$ resolution) & $11(8.2)$ & $7(6.5)$ & $3(11.1)$ & - \\
\hline $\operatorname{PCVCX} 2(\leq 50 \%$ resolution $)$ & $0(0)$ & $0(0)$ & $0(0)$ & - \\
\hline PCVCX3 (persistent or worsening changes) & $0(0)$ & $0(0)$ & $0(0)$ & - \\
\hline PCVCX4 (non-COVID-related changes) & $12(9.0)$ & $8(7.5)$ & $4(14.8)$ & - \\
\hline
\end{tabular}

*Unpaired t-test

${ }^{a}$ Mann-Whitney U test 
Table 2 Displaying symptom burden at follow-up, stratified by level of care, sex, and time to follow-up

\begin{tabular}{|c|c|c|c|c|c|c|c|c|c|}
\hline & $\begin{array}{l}\text { All Patients } \\
(n=134)\end{array}$ & $\begin{array}{l}\text { Ward-based } \\
(n=107)\end{array}$ & $\operatorname{ICU}(n=27)$ & $\begin{array}{l}\text { Male } \\
(n=88)\end{array}$ & $\begin{array}{l}\text { Female } \\
(n=46)\end{array}$ & $\begin{array}{l}\text { Follow-up } \\
47-75 \text { Days } \\
(n=7)\end{array}$ & $\begin{array}{l}\text { Follow-up } \\
76-100 \\
\text { Days } \\
(n=26)\end{array}$ & $\begin{array}{l}\text { Follow-up } \\
101-125 \\
\text { Days } \\
(n=78)\end{array}$ & $\begin{array}{l}\text { Follow-up } \\
126-167 \\
\text { Days }(n=23)\end{array}$ \\
\hline \multicolumn{10}{|c|}{ Symptoms at follow-up (\%) } \\
\hline $\begin{array}{l}\text { Breathless- } \\
\text { ness }\end{array}$ & $80(59.7)$ & $60(56.1)$ & $19(70.4)$ & $51(58.0)$ & $29(63.0)$ & $5(71.4)$ & $19(73.1)$ & $43(55.1)$ & $13(56.5)$ \\
\hline Myalgia & $69(51.5)$ & $53(49.5)$ & $16(59.3)$ & $39(44.3)$ & $30(65.2)$ & $6(85.7)$ & $18(69.2)$ & $33(42.3)$ & $12(52.2)$ \\
\hline Anxiety & $64(47.8)$ & $52(48.6)$ & $12(44.4)$ & $33(37.5)$ & $31(67.4)$ & $4(57.1)$ & $16(61.5)$ & $34(43.6)$ & $10(43.5)$ \\
\hline $\begin{array}{r}\text { Extreme } \\
\text { fatigue }\end{array}$ & $53(39.6)$ & $44(41.1)$ & $9(33.3)$ & $27(30.7)$ & $26(56.5)$ & $5(71.4)$ & $13(50.0)$ & $26(33.3)$ & $9(39.1)$ \\
\hline Low mood & $53(39.6)$ & $43(40.2)$ & $10(37.0)$ & $29(33.0)$ & $24(52.2)$ & $4(57.1)$ & $11(42.3)$ & $30(38.5)$ & $8(34.8)$ \\
\hline $\begin{array}{l}\text { Memory } \\
\text { impair- } \\
\text { ment }\end{array}$ & $50(37.3)$ & $43(40.2)$ & $7(25.9)$ & $24(27.3)$ & $26(56.5)$ & $3(42.9)$ & $12(46.2)$ & $24(30.8)$ & $11(47.8)$ \\
\hline $\begin{array}{l}\text { Sleep dis- } \\
\text { turbance }\end{array}$ & $47(35.1)$ & $37(34.6)$ & $10(37.0)$ & $24(27.3)$ & $23(50.0)$ & $4(57.1)$ & $11(42.3)$ & $27(34.6)$ & $5(21.7)$ \\
\hline Cough & $47(35.1)$ & $42(39.3)$ & $5(18.5)$ & $27(30.7)$ & $20(43.5)$ & $2(28.6)$ & $11(42.3)$ & $29(37.2)$ & $5(21.7)$ \\
\hline $\begin{array}{l}\text { Attention } \\
\text { deficit }\end{array}$ & $34(25.4)$ & $29(27.1)$ & $5(18.5)$ & $18(20.5)$ & $16(34.8)$ & $3(42.9)$ & 9 (34.6) & $16(20.5)$ & $6(26.1)$ \\
\hline $\begin{array}{l}\text { Pleuritic } \\
\text { chest } \\
\text { pain }\end{array}$ & $24(17.9)$ & $23(21.5)$ & $1(3.7)$ & $14(15.9)$ & $10(21.7)$ & $1(14.3)$ & $3(11.5)$ & $17(21.8)$ & $3(13.0)$ \\
\hline Sore throat & $17(12.7)$ & $12(11.2)$ & $5(18.5)$ & $10(11.4)$ & $7(15.2)$ & $2(28.6)$ & $4(15.4)$ & $8(10.2)$ & $3(13.0)$ \\
\hline Fever & $14(10.4)$ & $14(13.1)$ & $0(0)$ & $6(6.8)$ & $8(17.4)$ & $1(14.3)$ & $1(3.8)$ & $11(14.1)$ & $1(4.3)$ \\
\hline Anosmia & $13(9.7)$ & $13(12.1)$ & $0(0)$ & $8(9.1)$ & $5(10.9)$ & $0(0)$ & $3(11.5)$ & $8(10.2)$ & $2(8.7)$ \\
\hline $\begin{array}{l}\text { Cognitive } \\
\text { impair- } \\
\text { ment }\end{array}$ & $13(9.7)$ & $11(10.3)$ & $2(7.4)$ & $5(5.7)$ & $8(17.4)$ & $1(14.3)$ & $5(19.2)$ & $4(5.1)$ & $3(13.0)$ \\
\hline $\begin{array}{l}\text { Taste defi- } \\
\text { ciency }\end{array}$ & $12(9.0)$ & $11(10.3)$ & $1(3.7)$ & $8(9.1)$ & $4(8.7)$ & $0(0)$ & $4(15.4)$ & $6(7.7)$ & $2(8.7)$ \\
\hline Rash & $11(8.2)$ & $11(10.3)$ & $0(0)$ & $5(5.7)$ & $6(13.0)$ & $0(0)$ & $1(3.8)$ & $9(11.5)$ & $1(4.3)$ \\
\hline $\begin{array}{l}\text { Symptom } \\
\text { cluster } \\
\text { A }^{*}\end{array}$ & $41(30.6)$ & $34(31.8)$ & 7 (25.9) & 19 (21.6) & $22(47.8)$ & $4(57.1)$ & $13(50.0)$ & $18(23.1)$ & $6(26.1)$ \\
\hline $\begin{array}{l}\text { Symptom } \\
\text { cluster } \\
\mathrm{B}^{\mathrm{a}}\end{array}$ & $21(15.7)$ & $18(16.8)$ & $3(11.1)$ & $13(14.8)$ & $8(17.4)$ & 2 (28.6) & $4(15.4)$ & $10(12.8)$ & $5(21.7)$ \\
\hline $\begin{array}{l}\text { Symptom } \\
\text { cluster } \\
\mathrm{C}^{\mathrm{b}}\end{array}$ & $19(14.2)$ & $17(15.9)$ & $2(7.4)$ & $12(13.6)$ & $7(15.2)$ & $2(28.6)$ & $3(11.5)$ & $11(14.1)$ & $3(13.0)$ \\
\hline $\begin{array}{l}\text { EQ-5D-5L } \\
\text { index } \\
\text { value }\end{array}$ & $0.657(0.30)$ & $0.650(0.30)$ & $0.668(0.29)$ & $0.676(0.31)$ & $0.610(0.28)$ & $0.486(0.26)$ & $0.629(0.35)$ & $0.660(0.29)$ & $0.708(0.28)$ \\
\hline \multicolumn{10}{|c|}{ Median MRC Breathlessness Scale Score (range) } \\
\hline Before & $1(1-5)$ & $1(1-5)$ & $1(1-4)$ & $1(1-5)$ & $1(1-5)$ & $1(1-5)$ & $1(1-4)$ & $1(1-5)$ & $1(1-4)$ \\
\hline After & $2(1-5)$ & $2(1-5)$ & $2(1-5)$ & $2(1-5)$ & $3(1-5)$ & $3(2-5)$ & $2(1-5)$ & $2(1-5)$ & $2(1-5)$ \\
\hline
\end{tabular}

*Symptom cluster A = Myalgia, fatigue

${ }^{\text {a }}$ Symptom cluster $\mathrm{B}=$ Low mood, anxiety, sleep disturbance

${ }^{\mathrm{b}}$ Symptom cluster $\mathrm{C}=$ Memory impairment, attention deficit, cognitive impairment

Females were significantly more likely to report symptoms in cluster A, when compared to males $(p=<0.001)$. No significant differences between patients were observed for clusters B and C. 

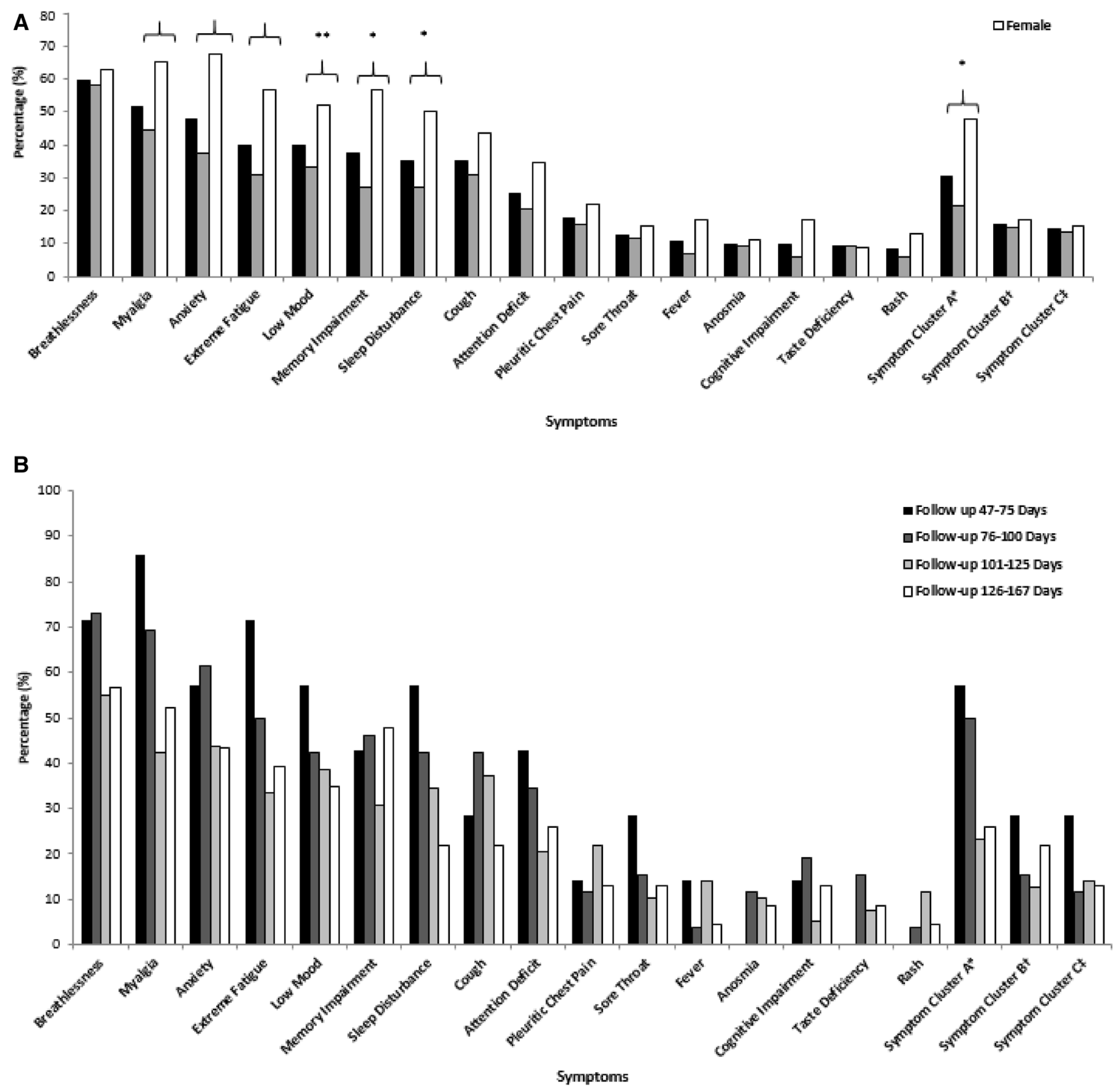

Fig. 1 a Cluster bar chart showing symptoms by sex. b A cluster bar chart showing symptom burden by time to follow-up. Asterisk denotes p-value on Chi-Square testing of $<0.05$, double asterisk denotes p-value on Chi-Square testing of $<0.001$

The co-occurrence matrix used to identify these clusters can be found in Fig. 2.

\section{Discussion}

Our results are consistent with previously published reports, with $86 \%$ of patients reporting at least 1 symptom at followup. Our study reinforces the lack of correlation between COVID-19 severity during hospitalisation and symptom burden at follow-up. Early descriptions of Long-COVID portray a miscellany of symptoms that are distinct from those of patients recovering from severe COVID-19 who required hospitalisation [12]. Could psychological/neuropsychiatric elements be predominant in Long-COVID, akin to posttraumatic distress? Similar post-traumatic syndromes, such as Gulf War Illness and post-9/11 syndrome, describe the occurrence of both physical and psychological symptoms in a similar pattern to what is being observed in Long-COVID $[13,14]$. We suggest the impact of a new, poorly understood, 


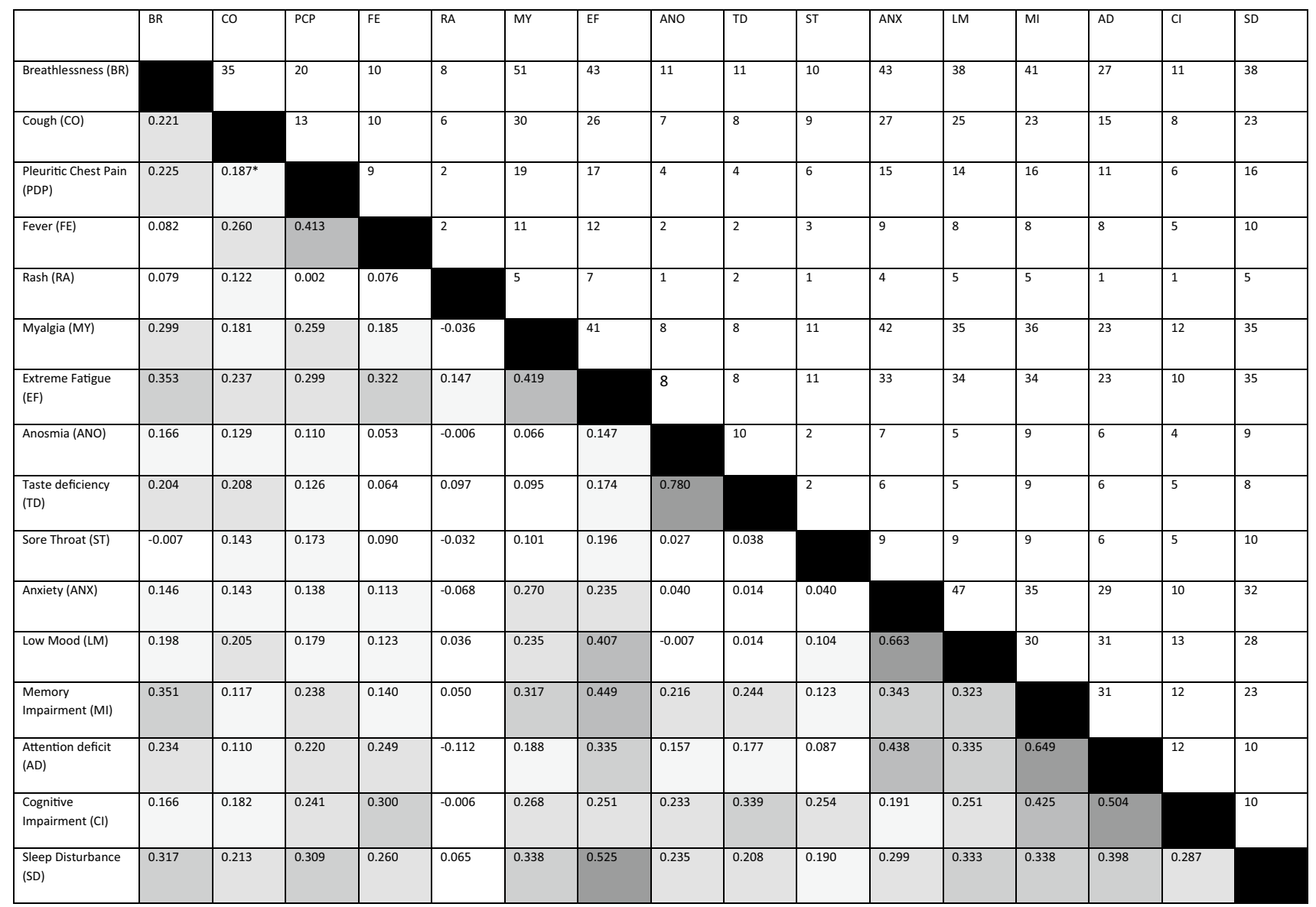

Fig. 2 Co-occurrence matrix, displaying both the frequency and the correlation coefficient of two co-occurring symptoms. Asterisk denotes correlation coefficient as calculated using regression analysis

and lethal virus and the associated societal disruption it has caused must not be understated. One must appreciate the importance of the biopsychosocial effects of COVID-19 and how they may precipitate the development of long-lasting symptoms affecting both physical and mental health.

With the paucity of evidence available, we question whether Long-COVID exists as a new disease with distinct pathophysiology. We suggest it is a new manifestation of a well-recognised phenomenon that can be observed after other traumatic events, as opposed to the persistent effect of COVID-19. The current evidence suggests that classic postviral respiratory symptoms, such as cough, are less frequent in Long-COVID patients [15]. Indeed, our study reinforces this, as we report a modest (35\%) prevalence of cough. For these reasons, we believe that resource allocation should prioritise rehabilitation and psychological support with less emphasis on advanced diagnostics and specialist respiratory services.

Data from the COVID symptom study App identified self-reported fatigue as the commonest complaint in a large group of Long-COVID patients [8]. If these symptoms were persistent at 4 months, they would meet the National Institute for Health and Care Excellence (NICE) diagnostic criteria for Chronic Fatigue Syndrome (CFS). A CFS diagnosis is considered when patients report post-exertional fatigue, cognitive difficulties, sleep disturbance, and chronic pain [16]. This is a remarkably similar symptom complex that we and others have observed in Long-COVID. There are also marked epidemiological similarities. Female preponderance is well described in the CFS literature [17] and obesity is also associated with greater symptom burden [18]. Both of these demographics were associated with greater symptom burden in our study, particularly those symptoms commonly described in CFS. Although the aetiology of CFS remains obscure, viral triggers have been hypothesised [19]. CFS services in the UK provide a tailored approach to the management of patients. A multifaceted service is provided, including symptom management, psychological treatments, employment support, and education about their condition [16]. It may be appropriate to incorporate these principles in Long-COVID service provision to ensure the effective management of our patients. 
Our study has limitations, including the inability to record any physiological data, such as peripheral oxygen saturation, at follow-up due to the virtual nature of the assessment. It has been observed that patients with no previous disability have demonstrated a deficit in physical performance. [20] Inclusion of these data may have helped us to ascertain whether there is a correlation between altered physiology, physical performance, and reported persistent symptoms. A further limitation of our study was the simple assessment of presence of persistent symptoms; we were only able to ascertain whether patients were experiencing symptoms and were unable to record the severity of each individual symptom.

\section{Conclusions}

We report data consistent with current evidence on the prevalence of post-COVID-19 symptom burden. We demonstrate an absence of association between symptom burden and radiographic or biochemical abnormality. We suggest that the phenomenon of Long-COVID may not be directly attributable to the effect of SARS-CoV-2, but rather the neuropsychiatric insults may play a greater role in its aetiology. Our observations help to inform decisions on service design and priorities for the care of these patients.

Supplementary Information The online version contains supplementary material available at https://doi.org/10.1007/s00408-021-00423-z.

\section{Compliance with Ethical Standards}

Conflict of interest All authors declare that they have no conflict of interest.

\section{References}

1. Wong, A., Shah, A., Johnston, J., Carlsten, C. and Ryerson, C., 2020. Patient-reported outcome measures after COVID-19: a prospective cohort study. European Respiratory Journal, p.2003276.

2. Carfì A, Bernabei R, Landi F, for the Gemelli Against COVID-19 Post-Acute Care Study Group. Persistent Symptoms in Patients After Acute COVID-19. JAMA. 2020;324(6):603-605.

3. Halpin SJ, McIvor C, Whyatt G, Adams A, Harvey O, McLean L, Walshaw C, Kemp S, Corrado J, Singh R, Collins T. Postdischarge symptoms and rehabilitation needs in survivors of COVID-19 infection: A cross-sectional evaluation. Journal of medical virology. 2020 Jul 30.

4. D'Cruz RF, Waller MD, Perrin F et al (2020) Chest radiography is a poor predictor of respiratory symptoms and functional impairment in survivors of severe COVID-19 pneumonia. ERJ Open Res. https://doi.org/10.1183/23120541.00655-2020
5. Mahase E (2020) Covid-19: What do we know about "long covid"? BMJ 14:370

6. https://www.england.nhs.uk/coronavirus/wp-content/uploads/ sites/52/2020/10/C0840_PostCOVID_assessment_clinic_guida nce_5_Nov_2020.pdf - Last Accessed 23/11/20

7. Mandal S, Barnett J, Brill SE, et al'Long-COVID': a crosssectional study of persisting symptoms, biomarker and imaging abnormalities following hospitalisation for COVID-19Thorax Published Online First: 10 November 2020

8. Sudre CH, Murray B, Varsavsky T, Graham MS, Penfold RS, Bowyer RC, Pujol JC, Klaser K, Antonelli M, Canas LS, Molteni E. Attributes and predictors of Long-COVID: analysis of COVID cases and their symptoms collected by the Covid Symptoms Study App. medRxiv. 2020 Jan 1.

9. Rockwood K, Song X, MacKnight C, Bergman H, Hogan DB, McDowell I, Mitnitski A (2005) A global clinical measure of fitness and frailty in elderly people. CMAJ 173(5):489-495

10. https://www.bsti.org.uk/covid-19-resources/covid-19-bsti-repor ting-templates/ - Last Accessed 18/11/2020

11. Nanni L, Brahnam S, Ghidoni S, Menegatti E, Barrier T (2013) Different approaches for extracting information from the cooccurrence matrix. PLoS ONE 8(12):e83554

12. Nabavi $\mathrm{N}$ (2020) Long covid: How to define it and how to manage it. BMJ 370:m3489

13. Neria Y, DiGrande L, Adams BG (2011) Posttraumatic stress disorder following the September 11, 2001, terrorist attacks: A review of the literature among highly exposed populations. Am Psychol 66(6):429

14. Kang HK, Natelson BH, Mahan CM, Lee KY, Murphy FM (2003) Post-traumatic stress disorder and chronic fatigue syndrome-like illness among Gulf War veterans: a population-based survey of 30,000 veterans. Am J Epidemiol 157(2):141-148

15. Dicpinigaitis PV, Canning BJ (2020) Is There (Will There Be) a Post-COVID-19 Chronic Cough? Lung. https://doi.org/10.1007/ s00408-020-00406-6

16. https://www.nice.org.uk/guidance/cg53/chapter/1-Guida nce\#diagnosis - Last Accessed 17/11/2020

17. Hempel S, Chambers D, Bagnall AM, Forbes C (2008) Risk factors for chronic fatigue syndrome/myalgic encephalomyelitis: a systematic scoping review of multiple predictor studies. Psychol Med 38(7):915

18. Flores S, Brown A, Adeoye S, Jason LA, Evans M (2013) Examining the impact of obesity on individuals with chronic fatigue syndrome. Workplace health \& safety 61(7):299-307

19. Yancey JR, Thomas SM (2012) Chronic fatigue syndrome: diagnosis and treatment. Am Fam Physician 86(8):741-746

20. Paneroni M, Simonelli C, Saleri M, Bertacchini L, Venturelli M, Troosters T, Ambrosino N, Vitacca M. Muscle strength and physical performance in patients without previous disabilities recovering from COVID-19 pneumonia. American Journal of Physical Medicine \& Rehabilitation. 2020 Nov 11.

Publisher's Note Springer Nature remains neutral with regard to jurisdictional claims in published maps and institutional affiliations. 